\title{
$\checkmark$ Research Square \\ Driving mechanisms of an extreme winter sea-ice breakup event in the Beaufort Sea
}

Jonathan Rheinlænder ( $\square$ jonathan.rheinlaender@nersc.no)

Nansen Environmental and Remote Sensing Center https://orcid.org/0000-0002-2544-2900

Richard Davy

NERSC https://orcid.org/0000-0001-9639-5980

Einar Ólason

Nansen Environmental and Remote Sensing Center

Pierre Rampal

CNRS, Institut de G' eophysique de l'Environnement

Clemens Spensberger

Geophysical Institute, University of Bergen, and Bjerknes Centre for Climate Research, Bergen

https://orcid.org/0000-0002-9649-6957

Timothy Williams

Nansen Environmental and Remote Sensing Center

\section{Article}

Keywords: storm-induced breakup, Arctic sea ice, ice growth

Posted Date: October 5th, 2021

DOI: https://doi.org/10.21203/rs.3.rs-952672/v1

License: (9) This work is licensed under a Creative Commons Attribution 4.0 International License.

Read Full License 


\title{
Driving mechanisms of an extreme winter sea-ice breakup event in the Beaufort Sea
}

\author{
Jonathan W. Rheinlænder ${ }^{1,2, *}$, Richard Davy ${ }^{1}$, Einar Olason ${ }^{1}$, Pierre Rampal ${ }^{4}$, Clemens \\ Spensberger ${ }^{3}$, and Timothy D. Williams ${ }^{1}$
}

\author{
${ }^{1}$ Nansen Environmental and Remote Sensing Center and Bjerknes Centre for Climate Research, Bergen, Norway \\ ${ }^{2}$ Department of Earth Science and Bjerknes Centre for Climate Research, University of Bergen, Bergen, Norway \\ ${ }^{3}$ Geophysical Institute, University of Bergen and Bjerknes Centre for Climate Research, Bergen, Norway \\ ${ }^{4} \mathrm{CNRS}$, Institut de Géophysique de l'Environnement, Grenoble, France \\ *jonathan.rheinlaender@nersc.no
}

10 ABSTRACT

The thick multi-year sea ice that once covered large parts of the Arctic Ocean is being replaced by thinner and weaker first-year ice, making it increasingly vulnerable to breakup by storms. Here we use a sea ice model to investigate the driving mechanisms behind a large sea-ice breakup event in the Beaufort Sea in response to a series of storms during February-March 2013. These simulations are the first to successfully reproduce the timing, location and propagation of sea-ice leads associated with storm-induced breakup. We found that rheology in the sea-ice model and horizontal resolution in the atmospheric model are both crucial in accurately simulating such breakup events. The sensitivity of the breakup to the initial sea-ice thickness indicates that large breakup events will become more frequent as Arctic sea ice continues to thin. Here we show that large breakup events during winter have a significant impact on ice growth through enhanced air-sea fluxes in open leads, and enhanced drift speeds which increase the export of old, thick ice out of the Beaufort Sea. Overall, this results in a thinner and weaker ice cover that may precondition earlier breakup in spring and accelerate sea-ice loss.

\section{Introduction}

Arctic sea ice is thinning ${ }^{1}$ as the area covered by thick multi-year ice (MYI) is decreasing ${ }^{2}$ and is being replaced by thinner first-year ice (FYI) which is more mobile and less dynamically stable ${ }^{3,4}$. This makes the ice cover more vulnerable to extreme storm events that break up the sea ice. In the Beaufort Sea in particular, the loss of MYI may contribute to the earlier onset of the melt season seen in recent years (arriving earlier by 5-7 days per decade) ${ }^{5}$. In addition, the frequency and intensity of Arctic storms has increased ${ }^{6,7}$, which has been linked to the reduced sea-ice extent in recent years ${ }^{8,9}$. In particular, wintertime cyclone activity in the Atlantic sector of the Arctic Ocean has increased by 6 events per decade during the period 1979-2015 ${ }^{10}$, while an increase of the number of cyclones entering the Beaufort Sea for the period 1948-2002 has been observed ${ }^{6}$. Climate model projections suggest that this trend will likely continue into the mid- $21^{\text {st }}$ century ${ }^{11,12}$. Intuitively, both strong winds and the thinning of sea ice are candidates as contributors to driving extreme sea-ice breakup events, but their relative importance and the implications for polar climate has not yet been established.

When sea ice breaks up it exposes the underlying warmer ocean within narrow, linear openings in the ice cover known as leads. This has important consequences for air-sea exchange, ocean eddies generation and dynamics, sea ice production and Arctic Ocean properties in general ${ }^{13-15}$, especially during the winter months when heat fluxes over sea ice are generally small ${ }^{16}$. In addition, breakup in winter weakens the ice cover and could precondition the minimum ice extent in summer and thus create a positive feedback to Arctic amplification ${ }^{17,18}$. Therefore, extreme breakup events are of crucial interest for understanding the seasonal and long-term evolution of Arctic sea ice, which in turn affects weather, ecosystems and local communities in polar regions and beyond ${ }^{19,20}$.

Several studies have investigated the impact of storms on Arctic sea ice cover ${ }^{14,21,22}$. However, when it comes to modelling individual breakup events, and accurately reproducing the spatial distribution of sea-ice leads, there have been few successful attempts $^{22,23}$ and breakup events are not well captured in current sea-ice and climate models ${ }^{24}$. This presents a critical gap in our understanding of atmosphere-ocean-ice interaction processes and limits the credibility of future projections of climate in polar and sub-polar regions ${ }^{25}$. This paper is the first step towards filling this gap by presenting high-resolution simulations using the next-generation sea-ice model — neXtSIM ${ }^{23,26,27}$ — focusing on a large breakup event that occurred in the Beaufort Sea during February-March 2013. This event, which was captured by the Visible Infrared Imaging Radiometer Suite (VIIRS) of the 
Suomi NPP satellite ${ }^{28}$, coincided with a high-pressure system centred over the northwest Beaufort Sea (Fig. 1a) that drove the strong winds and fractured the ice cover. The objective of this study is to identify the key factors driving such wintertime sea-ice breakup events and provide a first estimate of the consequences of these events for the Arctic sea ice volume budget.

\section{Simulating the $\mathbf{2 0 1 3}$ sea-ice breakup event}

We simulated the breakup event using the neXtSIM model in a stand-alone configuration, in the present case forced by the ERA5 atmospheric reanalysis downscaled using the polar-optimized version of the Weather Research and Forecasting model (Polar-WRF) to a horizontal resolution of $10 \mathrm{~km}$ (i.e. WRF10; see "Methods" for details). Snapshots of observed and simulated leads during the breakup event are shown in Fig. 1b and c for February 18, February 23 and March 1. The satellite observations ${ }^{29}$ show that a fracture was already present by mid-February at Point Barrow in the western Beaufort Sea within an area covered by FYI (Fig. 1b). Over the next few days, large pieces of ice started to break off and be transported towards the Chukchi Sea. On February 23 an extensive arch-shaped fracture about $1000 \mathrm{~km}$ long and $\sim 4 \mathrm{~km}$ wide had formed, extending across nearly the entire Beaufort Sea, with secondary fractures on the leeward side. By the end of February the fracturing had expanded towards Banks Island in the east, at which point the ice cover was broken up and consisted of a myriad of free-drifting plates and floes. The simulated lead distribution and propagation shows remarkably good agreement with the observations (Fig. 1c), with leads appearing as regions of low sea ice concentration in the otherwise dense pack ice. In particular, the model captures the characteristic arch-shaped wave of fractures, first opening close to Point Barrow in mid-February and then propagating progressively east towards Banks Island.

The ability of the model to reproduce the observed breakup pattern depends strongly on accurately capturing the location and propagation of strong winds. The storm-passage and the associated ice drift is shown in Fig. 2a and b, along a transect running perpendicular to the primary fracture propagation in the Beaufort Sea. By comparing the direction of wind vectors (Fig. 2a) relative to the lead propagation direction, we find that the fractures form as a consequence of failure under shear stress associated with winds blowing parallel to the Alaskan coast in a southwesterly direction, i.e. away from Banks Island, whereby ice breaks approximately tangentially to the coast ${ }^{30}$. Once the wind speed exceeds a critical value (about $10 \mathrm{~m} \mathrm{~s}{ }^{-1}$ ) the internal stresses in the ice pack become such that the ice starts to fracture in a step-like manner matching the timing of the storm-passage (Fig. 2b). This critical threshold likely depends on multiple factors including ice thickness and concentration, wind direction and sea-ice floe size distribution ${ }^{3,31}$.

Another important factor in getting the right characteristics of the breakup is the new brittle-like rheology formulation (here the Brittle Bingham-Maxwell - BBM ${ }^{32}$ ) employed in the neXtSIM simulations. In particular, the arch-shaped deformation (in response to accumulating sea ice damage) and threshold mechanics seen in both observations and the simulation is a behaviour that is characteristic of the brittle nature of sea-ice mechanics ${ }^{27,33}$. In comparison, this is not adequately resolved in traditional elastic-viscous-plastic (EVP) or modified EVP (m-EVP) models, which typically require being run with a horizontal resolution of about $1 \mathrm{~km}$ - between one and two orders of magnitude higher than what used in the latest CMIP6 climate models - in order to represent sea-ice deformation features at smaller scales ${ }^{22,24}$. This can be seen from the neXtSIM simulations performed using the EVP and m-EVP rheologies instead of the BBM (see Supplementary Figure 1). Both EVP and m-EVP simulate a much smoother ice velocity field and does not capture the fracture propagation as obtained with the BBM.

\section{Impact of atmospheric resolution on sea ice breakup}

Accurate representation of wind forcing plays a key role in modelling sea ice deformation, but this forcing depends on the atmospheric model and the resolution of the model. Regional atmospheric properties, such as storm dynamics and horizontal gradients are generally more skilfully reproduced at higher resolution ${ }^{34}$. To test how the simulated breakup is affected by the resolution of the atmospheric forcing we performed additional experiments with different resolutions of the Polar-WRF model $(10,20,40$ and $80 \mathrm{~km})$. Despite relatively modest differences in the location and amplitude of maximum winds for the different simulations (Supplementary Figure 2 and 3), we obtain major differences in the simulated breakup pattern. In Fig. 2c the propagation of leads in the Beaufort Sea is visualised by looking at the $5-\mathrm{cm} \mathrm{s}^{-1}$ ice velocity contour, which tracks the eastward movement of the primary fracture. This is compared to the observed leads from satellite (see "Methods"). Both simulations forced by the 10-km and 20-km resolution winds show the very characteristic progressive wave of fractures from Point Barrow to Banks Island which matches the timing of the observed sequence of lead openings quite well, although slightly faster than observed. Whereas for the simulations forced by low-resolution winds (40- and 80-km), the ice immediately breaks much further east closer to Banks Island instead of showing an eastward propagation of fractures as seen in the higher resolution runs, and in the observations.

The improved breakup pattern can be attributed primarily to the difference in the simulated winds in the Beaufort Sea at high and low resolutions. In particular, the propagation of the storm is better constrained at higher resolution (10- and 20-km), the gradients in the wind field are sharper, and high wind speeds are more localized, particularly along the coast and at Point 
Barrow where it creates strong local shear stresses on the ice (Supplementary Figure 2). In comparison, at lower resolution (40- and $80-\mathrm{km}$ ) stronger winds, exceeding $10 \mathrm{~m} \mathrm{~s}^{-1}$, extend further east into the central Beaufort Sea at the start of the breakup event and the storm-passage happens less gradually. Note that this difference is not purely due to the resolution of the wind field, but is related to how the atmospheric dynamics behave at these higher resolutions. The importance of capturing the proper atmospheric dynamics related to the storm was further demonstrated by running a simulation forced by the global ERA5 reanalysis at 31-km resolution ${ }^{35}$ and another simulation where we coarse-grained WRF10 to the WRF80 grid (not shown). Here we found that the ERA5 simulations performed similarly to the WRF80 despite the higher resolution of the ERA5 forcing (Supplementary Figure 3), whereas the WRF10 coarsened to the WRF80 resolution performed similarly to the WRF10 simulations. This suggests that not only the resolution, but also the quality/tuning of the atmospheric model (e.g. improved parameterisations optimised for polar regions) is an important factor for simulating ice deformation ${ }^{36}$.

\section{Thinning sea ice accelerates storm-induced breakup}

Following the minimum extent in 2012, the ice cover in the Beaufort Sea was exceptionally thin and weak in winter $2013^{37}$, which may have preconditioned the breakup. Indeed, and as suggested by P. Rampal and collaborators ${ }^{3}$, long-term sea-ice thinning could be expected to weaken the ice cover further and increase deformation rates. To test how the initial ice conditions affect the breakup, we first reduced the ice thickness at the start of the breakup by $50 \%\left(0.5^{*}\right.$ SIT; Fig. 3). Next, we consider what happens if the ice was thicker by increasing the initial thickness distribution by $50 \%(1.5 * \mathrm{SIT})$ and $100 \%(2.0 * \mathrm{SIT})$. The average thickness in the Beaufort Sea for the three scenarios is $0.69 \mathrm{~m}, 2.01 \mathrm{~m}$ and $2.75 \mathrm{~m}$ respectively (compared to $1.37 \mathrm{~m}$ in the control experiment). Thus, for $0.5^{*}$ SIT the winter ice cover mostly consists of thin FYI which is projected to occur before the end of 2100 by CMIP6 models (Supplementary Figure S4). The remaining two cases reflect sea ice conditions prior to the 2000's when the ice in the Beaufort Sea was considerably thicker (more than $2 \mathrm{~m}$ based on submarine measurements over the period $1975-2000^{38}$ ).

When the ice is thinner it breaks up more easily and becomes more mobile, while for thicker ice the threshold for initiating breakup is higher. This is because thicker ice cover has a higher mechanical strength compared to thin ice, limiting its fragmentation, which both control the overall ice mobility ${ }^{3}$. This relationship between thickness and mobility is reflected in the ratio between ice drift and wind speeds (Fig. 3a), which increases with thinner ice, consistent with observations showing that in areas covered by FYI, the ratio is relatively large ${ }^{39}$. As a result, the ice cover is more damaged when the ice is thin (SIT*0.5), with more leads (lead fraction increases by $\sim 3 \%$ ), while for thicker ice (SIT*1.5 and SIT*2.0) stronger winds $\left(>14 \mathrm{~m} \mathrm{~s}^{-1}\right.$ ) are required to break up the ice and there is a large reduction in the drift speed to wind speed ratio. The start of the breakup also occurs progressively later with increasing thickness (Fig. 3b), a direct consequence and illustration of thicker ice being more resistant to breakups. On February 21 for $1.5 *$ SIT and around March 1 for $2.0 *$ SIT. The location where the ice initially breaks also shifts from Point Barrow closer to Banks Island, which is where the winds are strongest. The fact that the breakup still occurs even if the ice is significantly thicker and stronger implies that storm dynamics did play a dominant role in the 2013 breakup event and that similar events likely occurred in the past too. Indeed, estimates of lead occurrence in the Beaufort Sea over the last 20 winters from 1993 to 2013 show that breakup events also took place several decades ago when the ice was significantly thicker ${ }^{30}$.

\section{Local impact on ice thickness and volume}

Opening of sea-ice leads exposes the relatively warm ocean to the cold atmosphere above, resulting in stronger heat and moisture transfer from the ocean to the atmosphere. Locally, heat fluxes upwards of $300 \mathrm{~W} \mathrm{~m}^{-2}$ are found in open leads in neXtSIM (Supplementary Figure 5), similar to those found from observations ${ }^{16}$. The enhanced ocean heat loss promotes new ice growth within the leads thereby affecting the ice thickness distribution in the Beaufort Sea (Fig. 4a). During the breakup the median thickness increases from $1.29 \mathrm{~m}$ to $1.45 \mathrm{~m}\left(16 \mathrm{~cm}\right.$ ), corresponding to a net increase of $113 \mathrm{~km}^{3}$ in ice volume (Fig. $4 \mathrm{~b}$ and Supplementary Table 1).

Changes in ice volume occur due to ice growth (thermodynamics) and ice advection (dynamics). First, we consider the thermodynamic growth in response to the sea ice breakup. The storm happened in mid-winter at a time when the ice cover is growing thicker. Thus, to isolate the storm-induced growth from the ice thickening in "normal" conditions, we estimated the growth for the leads and pack ice separately (see "Methods"), as shown in Fig. 4b. The total thermodynamic ice growth (leads + pack ice) in the Beaufort Sea from February 13 to March 13 is $346 \mathrm{~km}^{3}$. This corresponds to an average growth of $25.5 \mathrm{~cm}$ over the whole Beaufort Sea, and is dominated by ice growth in the pack ice which contributes about $80 \%\left(279.2 \mathrm{~km}^{3}\right)$ of the total growth. Thus, the ice formed in leads contributes with a $\sim 20 \%$ increase $\left(67 \mathrm{~km}^{3}\right)$ to the local ice volume. This gives an average growth rate of $\sim 20 \mathrm{~cm} \mathrm{day}^{-1}$ within leads (Supplementary Figure 6), which for instance is comparable to growth rates observed in open water due to supercooling ${ }^{40}$. 
Next, to fully understand the impact of the breakup on the sea ice mass budget we examine the ice transport in the Beaufort region (Fig. 4c). As the ice cover becomes more fractured and mobile, more ice is also transported out of the Beaufort Sea as a consequence of the strong (westerly) winds and enhanced drift speeds shown in Fig. 3a. During the storm passage there is a net ice export of $240 \mathrm{~km}^{3}$, implying that more than $2 / 3$ of the ice formed by thermodynamic processes is transported out of the region. Overall, the increased volume export dominates over the thermodynamic growth thereby contributing to decreasing ice volume locally (Fig. 4b). This indicates that extreme winter breakup events may have a negative impact on the regional sea ice mass balance, resulting in less ice altogether compared to years without any breakup. We find that, in the initial stage of the breakup, it is predominantly FYI ( $<1.6 \mathrm{~m}$ thick) located in the central- and southwestern Beaufort basin that is being exported westward into the Chukchi Sea (see inset in Fig. 4a). When the fractures reaches Banks Island on March 1 it mobilises the thicker, older ice $(>1.6 \mathrm{~m})$ which is subsequently transported to the Canadian Basin. This pattern is largely consistent with the climatological mean ice flow in the Beaufort Sea, following the anticyclonic motion of the Beaufort Gyre ${ }^{41}$. Towards the end of the breakup the ice flux decreases associated with a reversal of the winds to the southeast (Fig. 2a) driving enhanced transport of MYI located in north of Greenland into the Beaufort Sea where it replenishes the dynamic ice loss, but also becomes more vulnerable to summer melt ${ }^{42}$.

\section{Challenges simulating extreme breakup events}

Our findings show that we are able to successfully capture the main features of the 2013 breakup, and highlight the importance of the atmospheric forcing and sea-ice conditions as key components in preconditioning and triggering the event. When it comes to the long-term impacts of the breakup there are some notable limitations of the current study. In particular, the lack of atmospheric and oceanic feedbacks has potential implications for air-sea interactions and their wider impacts on Arctic sea ice. Opening of sea-ice leads has considerable influence on the atmospheric boundary layer (ABL) ${ }^{43}$. For example, the emission of oceanic heat within leads warms the ABL (near-surface temperature increases by more than $20^{\circ} \mathrm{C}$ over simulated leads; not shown) which could increase the convective potential of the storm, driving further breakup and enhancing ice production. On the other hand, low-level clouds are often found over leads ${ }^{14,28}$ further increasing the downward long-wave radiation which reduces surface heat loss and inhibits thermodynamic ice growth. Similarly, the presence of snow on ice, resulting from enhanced precipitation during storms, can significantly slow-down the thermodynamic growth process ${ }^{14}$, which would cause us to overestimate the ice growth associated with the breakup.

Storm-induced changes in the sea-ice state, e.g. from enhanced ridging or reduced concentration, will influence the atmosphere-ice momentum transfer ${ }^{44}$, but this is not captured when using a constant atmospheric drag coefficient. At the ice-ocean interface the opening of leads can trigger eddy generation through increased buoyancy flux which in turn affects large-scale ice dynamics and drift ${ }^{13}$. The increase in drift speeds promotes significant increase in ocean mixing and drives enhanced bottom melt by mixing up warmer water from below ${ }^{14,21}$. As most of these processes and feedbacks occur in areas of high deformation rates (shear or convergence) only models that properly capture small scale sea-ice dynamics can be used to study these processes. In this respect, a model like neXtSIM, which includes a brittle rheological framework based on damage propagation to simulate sea-ice dynamics, is a much more appropriate candidate ${ }^{23,27,32}$. Furthermore, they also occur on small spatial and temporal scales, thus highlighting the need for developing sub-grid scale parameterisations if such processes are to be included in global climate models.

\section{Potential implications for Arctic sea-ice loss}

There are two main competing effects when it comes to the impact of sea-ice breakup events on the Arctic sea ice mass balance. Opening of leads in winter increases ice production and therefore we could expect such events to have a positive impact on the Arctic volume budget. On the other hand, ice breakup increases the mean drift speed of the ice pack and with this there is a tendency towards stronger volume export out of the Arctic ${ }^{4}$. The seasonality, i.e. the time of year when the breakup occurs, is also important. Whereas breakup in winter results in enhanced ice growth, lead opening in summer, however, accelerates sea ice thinning by decreasing the albedo and allowing more shortwave absorption by the ocean ${ }^{3}$.

We cannot directly assess the impact of winter leads on the wider Arctic sea ice at seasonal time-scales or longer due to the absence of potentially important feedbacks detailed above, and the relatively short time frame considered here. However, recent findings suggest that that the downstream effects of sea-ice breakup in winter can lead to an overall reduction in Arctic sea ice in the long term. Arctic winter storms may precondition the ice cover for a faster summer melt by promoting enhanced lateral melt rates in deformed sea ice ${ }^{14}$. Similarly, more leads in winter may affect the evolution of Arctic sea ice throughout the melt season, as the thinner and weaker sea ice in refrozen leads is more vulnerable to atmospheric forcing (e.g., cyclones entering the Arctic in summer) ${ }^{17}$. This can lead to earlier breakup and increase the lead fraction in summer which accelerates the ice-albedo feedback and further loss of Arctic sea ice ${ }^{18}$. To put this into perspective, however, the Arctic sea ice volume 
actually increased in 2013 after the anomalously low melting in the summer ${ }^{45}$, implying that other factors (like atmospheric variability) are important for controlling year-to-year variations in the Arctic sea ice mass budget.

We have shown that the effect of storm-induced breakups is likely to become more pronounced in the future, as the ice pack transitions toward younger, thinner sea ice. Even if the frequency and intensity of Arctic storms remains unchanged, the thinning of sea ice alone will lead to more severe and frequent breakup events. However, the frequency of extreme cyclones entering the Arctic is also likely to increase in the future ${ }^{10}$ which will only increase the importance of cyclones on the sea ice mass budget. As sea ice in the Beaufort Sea continues to thin ${ }^{2}$, it becomes more vulnerable to storm-induced breakup during winter months and could accelerate the loss of MYI currently residing in the Central Arctic. These findings highlight that winter breakup events may lead to a faster reduction in Arctic sea ice volume than currently projected by coupled climate models ${ }^{46}$.

\section{Methods}

\section{Description of the neXtSIM sea-ice model}

Here we use the stand-alone-version of the sea-ice model neXtSIM to study the 2013 breakup event in the Beaufort Sea. NeXtSIM is a finite-element sea-ice model that uses a moving Lagrangian mesh ${ }^{26,27,32,47}$. The dynamical core of neXtSIM is a rheology with a brittle behaviour, whereby the ice in individual mesh triangles can "fail" if they experience too high a stress - then their internal stress drops towards zero and the applied stress must be supported by neighbouring triangles that may then fail as well. This behaviour leads to a cascade in damage and manifests in the production of linear kinematic features like cracks and leads. Such models are ideal for simulating breakup events like the one we are targeting in the 2013 winter.

The latest version of neXtSIM uses the BBM sea-ice rheology ${ }^{32}$, which mainly differs from previous versions of the rheology in the way it prevents excessive convergence - in the case of BBM, it uses a Bingham friction element that is independent of the damage parameter to do this, while previous versions used ice pressure terms in the sea-ice momentum balance. The simulation domain that we use covers the central Arctic and has a spatial resolution of about $10 \mathrm{~km}$ (approximate distance between nodes of the moving triangular mesh).

\section{Atmospheric and oceanic forcing}

The sea ice model receives daily-averaged ocean forcing fields (30-m-currents, surface temperature and salinity, and mixed layer depth) from the TOPAZ4 reanalysis for the sea ice and ocean ${ }^{48}$. For the atmosphere, we use hourly atmospheric forcing fields (10-m-winds, rainfall, snowfall, surface temperature, pressure, and specific humidity) from the polar-optimized version of the Weather Research and Forecasting model version 3.9.1 (Polar-WRF) ${ }^{36}$. The Polar-WRF atmospheric model is based on the standard WRF model, but has been optimized for polar applications by implementing a specification of sea-ice thickness and snow depth over sea ice. The vertical grid encompasses 60 hybrid model levels with a grid spacing of about 8-10 hPa in the lowest 3 levels. The value of the atmospheric drag coefficient is 0.0016 and is spatially uniform throughout the domain. WRF is configured following the Antarctic Mesoscale Prediction System. Both the oceanic and atmospheric forcing variables are interpolated temporally and spatially onto the model grid at run time using a linear and bilinear interpolation method, respectively.

The WRF output is a dynamical downscaling of the European Centre for Medium Range Weather Forecasts (ECMWF) operational analyses. The analyses provide the initial and 6-hourly boundary conditions of the WRF simulations. Further, the model interior is nudged towards the ECMWF analyses at scales larger than approx. $650 \mathrm{~km}$. We tested four different horizontal resolutions of the Polar-WRF downscaling $(10,20,40$ and $80 \mathrm{~km})$ to investigate the role of atmospheric resolution on simulating the 2013 breakup event. These are referred to as WRF10, WRF20, WRF40 and WRF80. In addition, to test the impact of using a polar-specific atmospheric model we performed a model run with the standard global reanalysis from ERA5 with a horizontal resolution of $31 \mathrm{~km}$ (Supplementary Figure 3).

\section{Initial conditions}

All the neXtSIM simulations are initialised with sea-ice fields from CS2-SMOS ${ }^{49}$ and are integrated from February 13 to March 13, 2013 covering the storm passage. The rationale for choosing this relatively short time period, is that we wish to focus primarily on the dynamics of the breakup. To address the long-term impacts will require running longer simulations ideally in a coupled framework over multiple years, which is beyond the current scope of this study. Instead we focus on the immediate impacts of the breakup event (i.e. on new ice growth, changes in ice drift, and ocean-atmosphere heat fluxes).

To explore how the breakup is affected by the initial sea-ice thickness conditions, we consider three cases: initial ice thickness (on February 13 ) is reduced uniformly by $50 \%(0.5 * \mathrm{SIT})$, and two cases where ice thickness is increased by $50 \%$ $(1.5 * \mathrm{SIT})$ and $100 \%(2.0 * \mathrm{SIT})$ respectively (see Supplementary Figure 4$)$. Note that the atmospheric forcing (i.e. wind strength etc.) is the same for all these experiments (WRF10). 


\section{Comparison to satellite observations}

To evaluate the simulated sea ice deformation and lead formation in neXtSIM, we take advantage of the lead detection product based on Moderate Resolution Imaging Spectroradiometer (MODIS) thermal infrared imagery ${ }^{29}$. This product provides daily wintertime Pan-Arctic categorical lead maps at 1-km resolution including lead class, artefacts, sea ice, clouds, open water and land mask, covering the period 2003-2015. The 2013 breakup event is clearly visible in the MODIS data (Fig. 1b) as long linear features within the Beaufort Sea ice pack. We compare the simulated lead propagation to the MODIS data in Fig. 2c by downsampling the high-resolution ArcLeads product $(1 \mathrm{~km})$ onto the neXtSIM grid. Grid-cells classified as open water (i.e. leads) are then plotted as black horizontal lines along the transect.

\section{Estimating storm-induced ice growth}

From the sea-ice model we obtain the thermodynamic growth rate (in $\mathrm{m} \mathrm{s}^{-1}$ ) at each model time-step for three ice thickness categories: new ice (ice formed in open water due to supercooling), young ice (ice thinner than $\sim 25 \mathrm{~cm}$ ) and old ice (ice thicker than $\sim 25 \mathrm{~cm}$ ). Generally, it is assumed that the growth in leads consists of frazil ice growth in open water and young ice formation, whereas the growth of old ice typically occurs in the pack ice. The total cumulative volume growth is then calculated for each of these categories by multiplying the growth in meters by the grid cell area and summing each cell in the Beaufort Sea region. Note that the dynamic thickening (e.g. due to ridging) is not considered in the growth estimates, but could be considerable within leads ${ }^{50}$.

\section{References}

1. Meier, W. Losing Arctic sea ice: Observations of the recent decline and the long-term context. In Thomas, D. (ed.) Sea Ice, 290-303 (Wiley Blackwell, Hoboken, 2017), third edit edn.

2. Kwok, R. Arctic sea ice thickness, volume, and multiyear ice coverage: Losses and coupled variability (1958-2018), DOI: 10.1088/1748-9326/aae3ec (2018).

3. Rampal, P., Weiss, J. \& Marsan, D. Positive trend in the mean speed and deformation rate of Arctic sea ice, 1979-2007. J. Geophys. Res. 114, C05013, DOI: 10.1029/2008JC005066 (2009).

4. Zhang, J., Lindsay, R., Schweiger, A. \& Rigor, I. Recent changes in the dynamic properties of declining Arctic sea ice: A model study. Geophys. Res. Lett. 39, 2012GL053545, DOI: 10.1029/2012GL053545 (2012).

5. Johnson, M. \& Eicken, H. Estimating Arctic sea-ice freeze-up and break-up from the satellite record: A comparison of different approaches in the Chukchi and Beaufort Seas. Elem. Sci. Anthropocene 2016, 000124, DOI: 10.12952/journal. elementa.000124 (2016).

6. Zhang, X., Walsh, J. E., Zhang, J., Bhatt, U. S. \& Ikeda, M. Climatology and interannual variability of Arctic cyclone activity: 1948-2002. J. Clim. 17, 2300-2317, DOI: 10.1175/1520-0442(2004)017<2300:CAIVOA>2.0.CO;2 (2004).

7. Sepp, M. \& Jaagus, J. Changes in the activity and tracks of Arctic cyclones. Clim. Chang. 2010 105:3 105, 577-595, DOI: 10.1007/S10584-010-9893-7 (2010).

8. Moore, G. W. K. The December 2015 North Pole Warming Event and the Increasing Occurrence of Such Events. Sci. Reports 2016 6:1 6, 1-11, DOI: 10.1038/srep39084 (2016).

9. Koyama, T., Stroeve, J., Cassano, J. \& Crawford, A. Sea Ice Loss and Arctic Cyclone Activity from 1979 to 2014. J. Clim. 30, 4735-4754, DOI: 10.1175/JCLI-D-16-0542.1 (2017).

10. Rinke, A. et al. Extreme cyclone events in the Arctic: Wintertime variability and trends. Environ. Res. Lett. 12, 094006, DOI: 10.1088/1748-9326/aa7def (2017).

11. Mioduszewski, J., Vavrus, S. \& Wang, M. Diminishing Arctic Sea Ice Promotes Stronger Surface Winds. J. Clim. 31, 8101-8119, DOI: 10.1175/JCLI-D-18-0109.1 (2018).

12. Akperov, M. et al. Future projections of cyclone activity in the Arctic for the 21 st century from regional climate models (Arctic-CORDEX). Glob. Planet. Chang. 182, 103005, DOI: 10.1016/j.gloplacha.2019.103005 (2019).

13. Cohanim, K., Zhao, K. X. \& Stewart, A. L. Dynamics of Eddies Generated by Sea Ice Leads. J. Phys. Oceanogr. 51, 3071-3092, DOI: 10.1175/JPO-D-20-0169.1 (2021).

14. Graham, R. M. et al. Winter storms accelerate the demise of sea ice in the Atlantic sector of the Arctic Ocean. Sci. Reports 9, 1-16, DOI: 10.1038/s41598-019-45574-5 (2019).

15. Nguyen, A. T., Menemenlis, D. \& Kwok, R. Improved modeling of the Arctic halocline with a subgrid-scale brine rejection parameterization. J. Geophys. Res. 114, C11014, DOI: 10.1029/2008JC005121 (2009). 
16. Andreas, E. L. \& Cash, B. A. Convective heat transfer over wintertime leads and polynyas. J. Geophys. Res. Ocean. 104, 25721-25734, DOI: 10.1029/1999JC900241 (1999).

17. Zhang, Y., Cheng, X., Liu, J. \& Hui, F. The potential of sea ice leads as a predictor for summer Arctic sea ice extent. Cryosphere 12, 3747-3757, DOI: 10.5194/tc-12-3747-2018 (2018).

18. Dai, A., Luo, D., Song, M. \& Liu, J. Arctic amplification is caused by sea-ice loss under increasing CO 2. Nat. Commun. 10, 1-13, DOI: 10.1038/s41467-018-07954-9 (2019).

19. Vihma, T. Effects of Arctic sea ice decline on weather and climate: A review. Surv Geophys. 1175-1214 (2014).

20. Forbes, B. C. et al. Sea ice, rain-on-snow and tundra reindeer nomadism in Arctic Russia. Biol. Lett. 12, DOI: 10.1098/ rsbl.2016.0466 (2016).

21. Zhang, J. et al. The impact of an intense summer cyclone on 2012 Arctic sea ice retreat. Geophys. Res. Lett 40, DOI: $10.1002 /$ grl.50190 (2013).

22. Wang, Q., Danilov, S., Jung, T., Kaleschke, L. \& Wernecke, A. Sea ice leads in the Arctic Ocean: Model assessment, interannual variability and trends. Geophys. Res. Lett. 43, 7019-7027, DOI: 10.1002/2016GL068696 (2016).

23. Ólason, E., Rampal, P. \& Dansereau, V. On the statistical properties of sea-ice lead fraction and heat fluxes in the arctic. Cryosphere 15, 1053-1064, DOI: 10.5194/tc-15-1053-2021 (2021).

24. Spreen, G., Kwok, R., Menemenlis, D. \& Nguyen, A. T. Sea-ice deformation in a coupled ocean-sea-ice model and in satellite remote sensing data. The Cryosphere 11, 1553-1573, DOI: 10.5194/tc-11-1553-2017 (2017).

25. Notz, D. \& Stroeve, J. Observed Arctic sea-ice loss directly follows anthropogenic CO2 emission. Science 354, 747-750, DOI: 10.1126/SCIENCE.AAG2345 (2016).

26. Rampal, P., Bouillon, S., Ólason, E. \& Morlighem, M. NeXtSIM: A new Lagrangian sea ice model. Cryosphere 10, 1055-1073, DOI: 10.5194/tc-10-1055-2016 (2016).

27. Rampal, P. et al. On the multi-fractal scaling properties of sea ice deformation. Cryosphere 13, 2457-2474, DOI: 10.5194/tc-13-2457-2019 (2019).

28. Beitsch, A., Kaleschke, L. \& Kern, S. Investigating High-Resolution AMSR2 Sea Ice Concentrations during the February 2013 Fracture Event in the Beaufort Sea. Remote. Sens 6, 6, DOI: 10.3390/rs6053841 (2014).

29. Willmes, S. \& Heinemann, G. Pan-arctic lead detection from MODIS thermal infrared imagery. Annals Glaciol. 56, 29-37, DOI: 10.3189/2015AoG69A615 (2015).

30. Lewis, B. J. \& Hutchings, J. K. Leads and Associated Sea Ice Drift in the Beaufort Sea in Winter. J. Geophys. Res. Ocean. 124, 3411-3427, DOI: 10.1029/2018JC014898 (2019).

31. Stern, H. L. et al. Seasonal evolution of the sea-ice floe size distribution in the Beaufort and Chukchi seas. Elem. Sci. Anthropocene 6, DOI: 10.1525/ELEMENTA.305 (2018).

32. Olason, E. et al. A new brittle rheology and numerical framework for large-scale sea-ice models. ESSOAr DOI: 10.1002/ESSOAR.10507977.1 (2021).

33. Schulson, E. M. Fracture of Ice and other Coulombic Materials. Mech. Nat. Solids 177-202, DOI: 10.1007/ 978-3-642-03578-4_8 (2009).

34. Lindsay, R., Wensnahan, M., Schweiger, A. \& Zhang, J. Evaluation of seven different atmospheric reanalysis products in the arctic. J. Clim. 27, 2588-2606, DOI: 10.1175/JCLI-D-13-00014.1 (2014).

35. Hersbach, H. et al. The ERA5 global reanalysis. Q. J. Royal Meteorol. Soc. 146, 1999-2049, DOI: 10.1002/qj.3803 (2020).

36. Hines, K. M. et al. Sea ice enhancements to polar WRF. Mon. Weather. Rev. 143, 2363-2385, DOI: 10.1175/ MWR-D-14-00344.1 (2015).

37. Parkinson, C. L. \& Comiso, J. C. On the 2012 record low Arctic sea ice cover: Combined impact of preconditioning and an August storm. Geophys. Res. Lett. 40, 1356-1361, DOI: 10.1002/grl.50349 (2013).

38. Rothrock, D. A., Percival, D. B. \& Wensnahan, M. The decline in arctic sea-ice thickness: Separating the spatial, annual, and interannual variability in a quarter century of submarine data. J. Geophys. Res. 113, C05003, DOI: 10.1029/2007JC004252 (2008).

39. Maeda, K., Kimura, N. \& Yamaguchi, H. Temporal and spatial change in the relationship between sea-ice motion and wind in the arctic. Polar Res. 39, DOI: 10.33265/polar.v39.3370 (2020). 
40. Skogseth, R., Nilsen, F. \& Smedsrud, L. H. Supercooled water in an Arctic polynya: observations and modeling. J. Glaciol. 55 (2009).

41. Howell, S. E. L., Brady, M., Derksen, C. \& Kelly, R. E. J. Recent changes in sea ice area flux through the Beaufort Sea during the summer. J. Geophys. Res. Ocean. 121, 2659-2672, DOI: 10.1002/2015JC011464 (2016).

42. Kwok, R. \& Cunningham, G. F. Contribution of melt in the Beaufort Sea to the decline in Arctic multiyear sea ice coverage: 1993-2009. Geophys. Res. Lett. 37, DOI: 10.1029/2010GL044678 (2010).

43. Lüpkes, C., Vihma, T., Birnbaum, G. \& Wacker, U. Influence of leads in sea ice on the temperature of the atmospheric boundary layer during polar night. Geophys. Res. Lett. 35, 3805, DOI: 10.1029/2007GL032461 (2008).

44. Martin, T., Tsamados, M., Schroeder, D. \& Feltham, D. L. The impact of variable sea ice roughness on changes in Arctic Ocean surface stress: A model study. J. Geophys. Res. Ocean. 121, 1931-1952, DOI: 10.1002/2015JC011186 (2016).

45. Tilling, R. L., Ridout, A., Shepherd, A. \& Wingham, D. J. Increased Arctic sea ice volume after anomalously low melting in 2013. Nat. Geosci. 8, 643-646, DOI: 10.1038/ngeo2489 (2015).

46. Davy, R. \& Outten, S. The arctic surface climate in CMIP6: Status and developments since CMIP5. J. Clim. 33, 8047-8068, DOI: 10.1175/JCLI-D-19-0990.1 (2020). 1912.11654.

47. Bouillon, S. \& Rampal, P. Presentation of the dynamical core of neXtSIM, a new sea ice model. Ocean. Model. 91, 23-37, DOI: 10.1016/j.ocemod.2015.04.005 (2015).

48. Sakov, P. et al. TOPAZ4: An ocean-sea ice data assimilation system for the North Atlantic and Arctic. Ocean. Sci. 8, 633-656, DOI: 10.5194/os-8-633-2012 (2012).

49. Ricker, R. et al. A weekly Arctic sea-ice thickness data record from merged CryoSat-2 and SMOS satellite data. Cryosphere 11, 1607-1623, DOI: 10.5194/tc-11-1607-2017 (2017).

50. Hutchings, J. K. \& Hibler, W. D. Small-scale sea ice deformation in the Beaufort Sea seasonal ice zone. J. Geophys. Res. 113, C08032, DOI: 10.1029/2006JC003971 (2008).

\section{Author contributions statement}

J.W.R designed the experiments, carried out the neXtSIM simulations, analysed the model outputs, made all the figures (except Supplementary Figure 4e which was done by R.D.) and wrote the paper. E.O., R.D. and P.R. helped in developing this study that is based on the original idea of P.R., and participated in constructive discussions that helped improve the paper. C.S. performed the simulations of the Polar WRF model. T.W. helped set up the neXtSIM experiments, and contributed to writing and discussions. All authors reviewed the manuscript. 


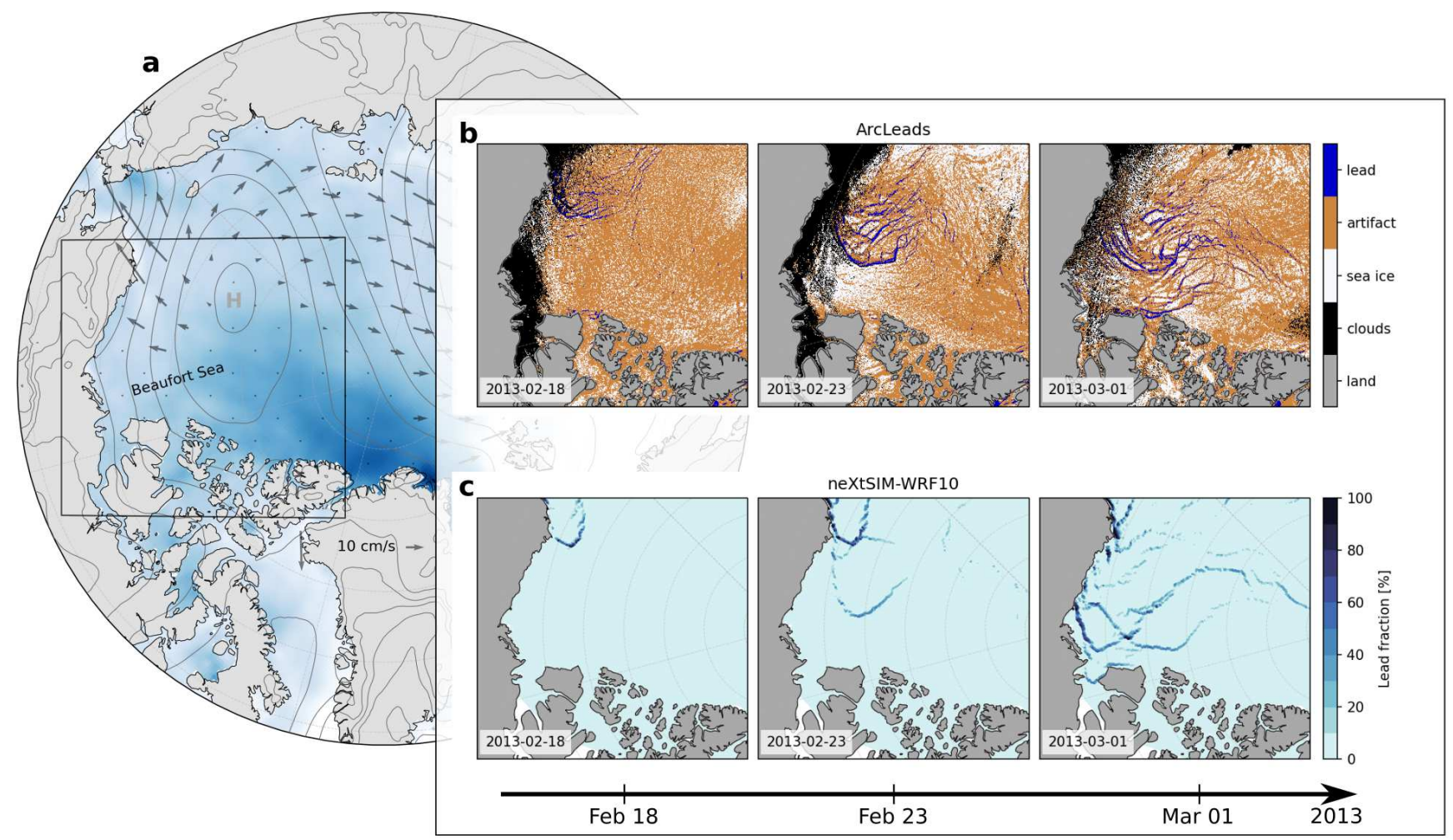

Figure 1. Extreme breakup of the Beaufort Sea winter ice cover (a) Schematic map of the Arctic Ocean with the observed winter sea-ice thickness from CS2-SMOS in colors and the ice flow field from neXtSIM on February 23 shown by arrows. Solid, grey lines represents mean sea-level pressure from ERA5. (b) Daily categorical lead map based on satellite data $(\text { MODIS })^{29}$, where blue colors corresponds to sea ice leads. (c) Simulated lead fraction (in \%) using the 10-km Polar-WRF downscalling ("WRF10") as the atmospheric forcing. The lead fraction is calculated as the combined fraction of open-water and sea ice thinner than $\sim 25 \mathrm{~cm}$ in each grid cell (1-sic + sic_thin). Both the observed and simulated sea-ice leads are shown on February 18, February 23 and March 1 in the Beaufort Sea during the 2013 breakup event. ERA5 data in a were obtained from the Copernicus Climate Change Service Climate Date Store. A time-lapse of the simulated and observed breakup event can be found in the Supplementary Movie 1 and 2. 


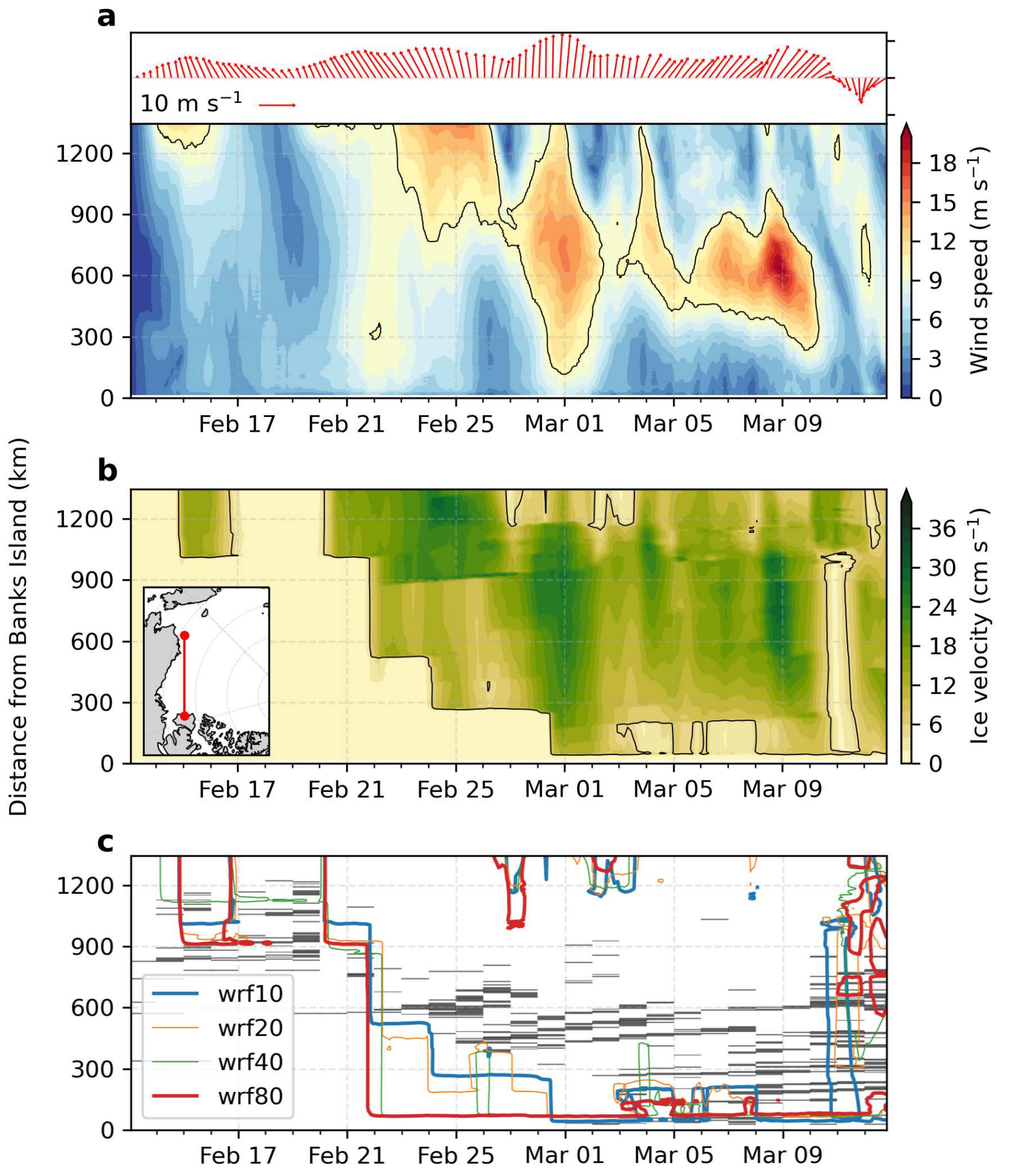

Figure 2. Time series of simulated winds and ice drift in the Beaufort Sea during the breakup event. (a) wind speed and direction (red arrows), (b) sea-ice velocity, (c) sea-ice lead propagation simulated with different atmospheric resolutions (coloured lines) indicated by the 5- $\mathrm{cm} \mathrm{s}^{-1}$ ice velocity contour. Detected sea-ice leads based on the ArcLeads product are shown by black lines ${ }^{29}$. All variables are calculated along a transect running from the western Beaufort Sea (close to Point Barrow) to Banks Island in the east. The inset in $\mathbf{b}$ indicates its geographical position. Black lines in $\mathbf{a}$ and $\mathbf{b}$ represent the 10-m $\mathrm{s}^{-1}$ wind-speed and $5-\mathrm{cm} \mathrm{s}^{-1}$ ice velocity, respectively. Vectors in a shows the average wind speed along the transect, with the direction relative to the transect. 

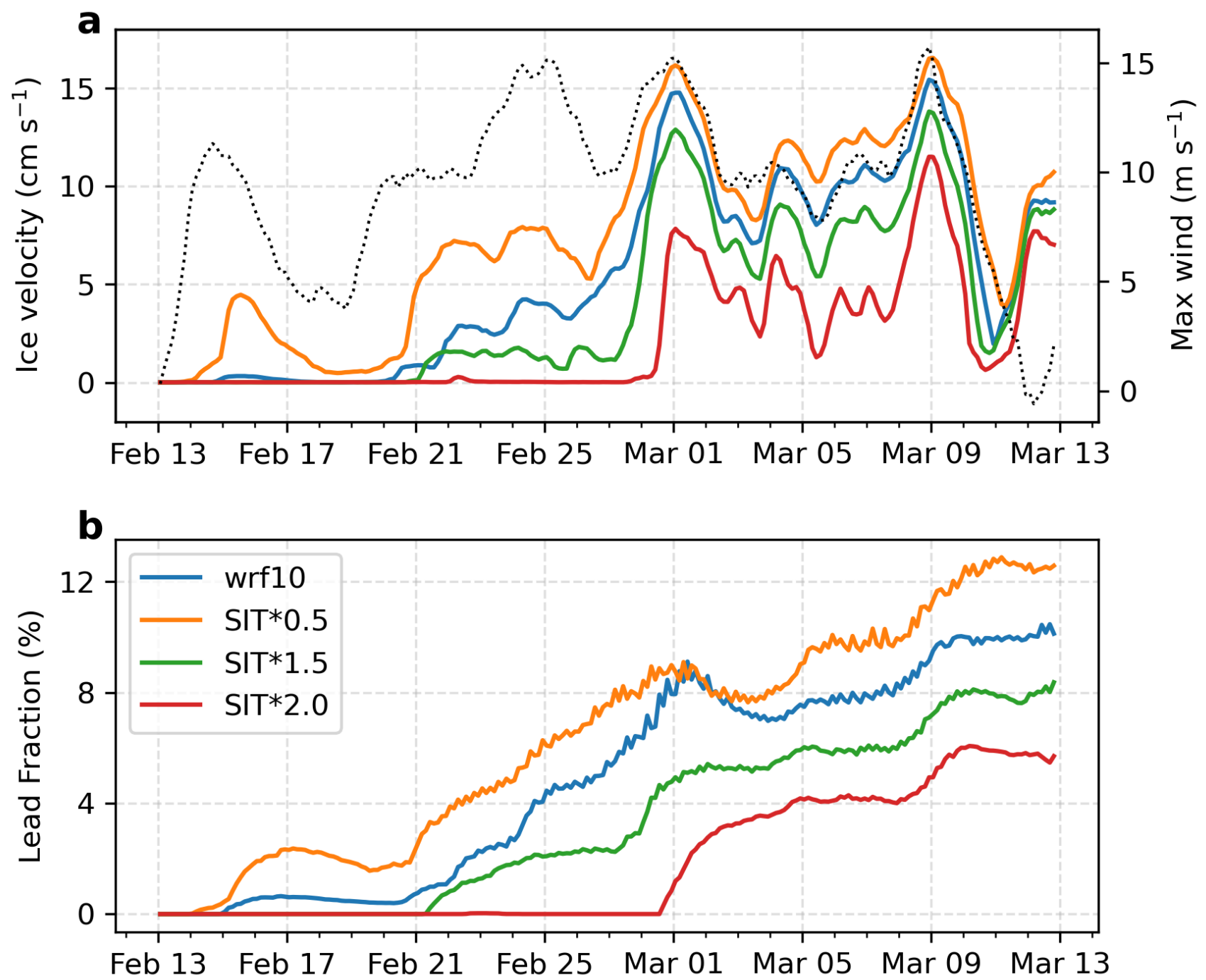

Figure 3. Relationship between sea ice thickness and extreme breakup events. (a) Time series of mean ice velocities averaged over the Beaufort Sea and maximum winds (grey dashed line) in the direction along-transect (inset in Fig. 2b). (b) Average lead fraction (as a $\%$ of the total Beaufort Sea area). Here, a grid cell is considered a lead when the combined concentration of open-water and thin ice (less than $\sim 25 \mathrm{~cm}$ ) is larger than $5 \%$. Otherwise it is considered pack ice. The area of the Beaufort Sea region is indicated in the inset in Fig. 4a. 

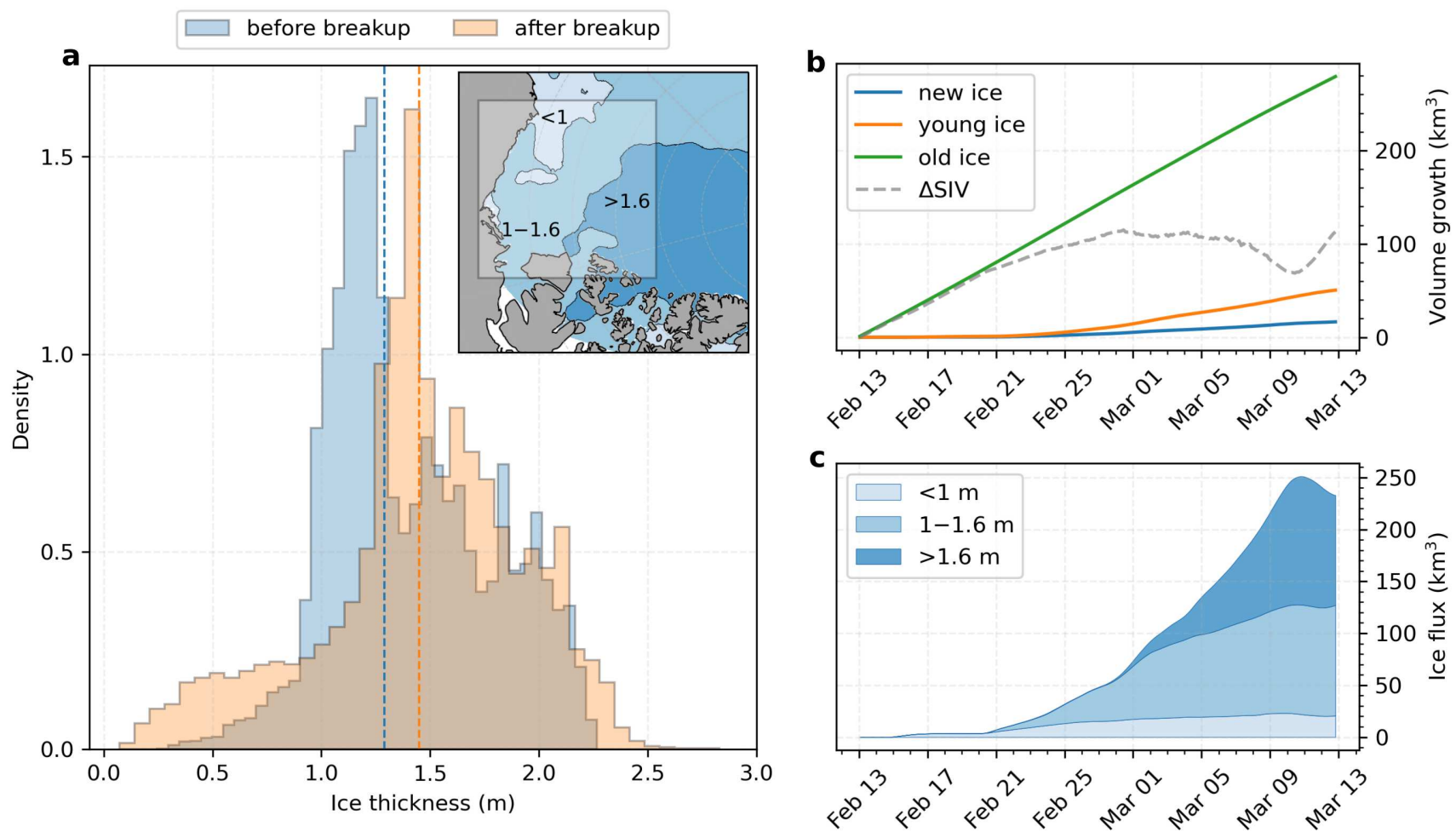

Figure 4. Impact of storm-induced sea-ice breakup on ice growth and ice export. (a) Histograms of the normalised sea-ice thickness in the Beaufort Sea region before (blue) and after (orange) the breakup event. (b) The cumulative ice volume growth in the Beaufort Sea calculated for three different ice categories: new ice (ice formed in open-water; blue line), young ice (orange line) and old ice (green line). See "Methods" for specific details. The dashed grey line represents the change in Beaufort ice volume $(\Delta \mathrm{SIV})$ relative to the start of the simulation, and is the combination of dynamic and thermodynamic process, i.e. ice import/export and ice growth. (c) Time series of sea-ice volume flux (in $\mathrm{km}^{3}$ ), where positive values corresponds to an export of ice out of the Beaufort Sea. The total flux is split into contributions from newly formed ice (SIT $<1$ $\mathrm{m})$, FYI $(1>\mathrm{SIT}<1.6 \mathrm{~m})$ and MYI $(\mathrm{SIT}>1.6 \mathrm{~m})$. All the data are based on the WRF10 experiment. The inset in a outlines the Beaufort Sea area with coloured contours showing the initial sea-ice thickness (on February 13) corresponding to the thickness classes used in $\mathbf{c}$. 


\section{Supplementary Files}

This is a list of supplementary files associated with this preprint. Click to download.

- breakuppaperNatureGeosciSupplementary.pdf

- SupplementaryMovieS1.mp4

- SupplementaryMovieS2.mov 